\title{
Palabras na penumbra. Un achegamento á ideoloxía e á estética de Xohán Casal ${ }^{1}$
}

\author{
M. ${ }^{\text {a Teresa Bermúdez Montes }}$ \\ (Universidade de Vigo) \\ bermudezteresa@uvigo.es
}

\begin{abstract}
Resumo: O pensamento político e estético Xohán Casal, autor encadrado na nova narrativa galega, era practicamente descoñecido ata hai ben pouco tempo. Nas súas cartas, borradores e diarios persoais (Real Academia Galega) desvélase de xeito nidio a súa ollada sobre o mundo a través dun pensamento autónomo: abrollan así o seu persoal compromiso con Galicia, un posicionamento político orientado á acción ou un particular concepto da galeguidade e da súa materialización na literatura.
\end{abstract}

Palabras clave: Xohán Casal, nova narrativa galega, narrativa galega século $\mathrm{XX}$, paisaxe.

\begin{abstract}
Xohan Casal's political ideology and aesthetic was not well known until a few years ago. Casal was an young, early dead writer traditonally included in the galician nova narrativa (new narrative). In his personal letters, rough drafts, diaries and other texts (Real Academia Galega, A Coruña), he shows cogently his autonomous and particular thinking about Galicia, Galician identity, Galician politics and Galician literature.
\end{abstract}

Keywords: Xohán Casal, Galician nova narrativa, XXth century Galician narrative, landscape.

\section{INTRODUCIÓN}

Xohán Casal (1935-1960) é, sen dúbida, un autor de marcada singularidade e difícil clasificación. A isto contribúe fundamentalmente a orixinalidade da súa obra publicada, O camiño de abaixo (1970), escolmada por Reimundo Patiño e

${ }^{1}$ Queremos deixar patente o noso agradecemento a todo o persoal do Arquivo da Real Academia Galega, pola súa amabilidade, eficiencia e dispoñibilidade. 
Isaac Díaz Pardo e editada postumamente. Á escaseza de estudos sobre a súa figura tampouco é allea a súa particular peripecia vital — dominada por unha enfermidade que limitaba as súas actividades e que lle provocou unha morte temperá- e o feito de non pertencer ao círculo santiagués que se aglutinaba darredor de Ramón Piñeiro e a editorial Galaxia, nos escuros anos da noite de pedra. Sen dúbida, Casal é un autor periférico no sistema literario galego, por varios motivos e desde diferentes ópticas. Mesmo na especialmente difícil conxuntura producida pola ditadura franquista e malia desenvolverse nun ambiente social fortemente castelanizado, este autor loitou por construír e por aplicar unha visión propia da literatura galega, absorbendo lecturas, escolmando ideas sobre estética e política e expoñéndoas en escritos de carácter privado.

Desde a primavera de 2010 están dispoñibles para os investigadores na Real Academia Galega diversos textos de Xohán Casal, na súa meirande parte borradores de textos literarios, xornais e correspondencia, así como anotacións e reflexións. Estes escritos do malogrado autor d'O camiño de abaixo foran conservados por Reimundo Patiño e a súa familia, ata o de agora.

Estes materiais presentan un retrato completo e poliédrico do home e do escritor, marcado pola loita para configurar o seu posicionamento ético e estético desde unha decidida autodefinición galega e galeguista. Os textos confirman lecturas, profundan nas preocupacións e na explicación das claves temáticas das súas obras ou revelan facetas inéditas.

En definitiva, as novas fontes de documentación ofrecen unha autopoética intensa e cargada de humanidade, descarnada e honesta ata a contradición, froito dun esforzo de Casal para comprender o panorama literario galego, para situarse nel e para traballar como escritor galego contribuíndo á consolidación do sistema literario e da identidade nacional.

Seguindo as dúas tendencias que estableceu González Millán, a obra de Casal pretendía situarse no eixo da literatura nacional, máis do que no nacionalismo literario (González Millán 1994). Mais esta era a época do culturalismo piñeirista que, como coinciden todos os autores en sinalar, pretendeu cinxir a reivindicación nacional ao campo da cultura, dada a potente represión franquista contra as nacionalidades históricas. Como veremos ao longo deste traballo, Casal loita desde o seu illamento por elaborar un posicionamento persoal, non sometido ás directrices da «mesa braseiro», senón baseándose nas propias lecturas e reflexións, contrastadas coas conversas cos mozos do seu tempo (Xosé Luís Franco Grande, Manuel María Fernández Teixeiro e, por suposto, Reimundo Patiño).

Recóllense a través das páxinas conservadas na Real Academia Galega datos relevantes para situar a Xohán Casal no campo literario galego. Así, fornecen información nova sobre os seus contactos cos escritores e intelectuais contemporáneos (Galicia e Bos Aires), así como as súas converxencias e diverxencias con eles (Piñeiro, Franco Grande, Patiño, Aranguren...). Tamén se atopan datos relevantes sobre as súas ideas, posicionamentos e opinións respecto de política e estética, sobre as súas preocupacións relixiosas e existenciais e as súas lecturas e preferencias artísticas. 
Neste traballo centrarémonos no estudo dos aspectos do pensamento casaliano presentes en dous dos textos inéditos (ver anexos) que se atopan nos Arquivos da Real Academia Galega, onde son conservados, e que transcribimos. Na nosa consideración, salienta nestes textos o tratamento de cuestións fundamentais como a reflexión sobre o concepto de paisaxe ${ }^{2}$ e a necesidade de reflectir na narrativa a Galicia urbana, por unha banda, e a vinculación entre galeguismo e esquerda, por outra. Para alén destes temas, os textos tratan outras cuestións de interese, fornecen informacións valiosas sobre as lecturas do autor e abren interesantes vías de investigación. Neste traballo, apenas damos á luz os textos, acompañados dunha contextualización e dunha primeira aproximación á análise do seu contido.

\section{CONCEPTO DE LITERATURA GALEGA}

Diferentes autores, entre os que cabe salientar a Antón Figueroa, teñen posto xa de manifesto a importancia determinante da creación dunhas «regras da arte» no desenvolvemento dunha literatura emerxente, sobre todo na liña do nacionalismo literario, necesario para chegar á literatura nacional (González Millán 1994).

Como é ben sabido, a arte, quizais sobre todo a literatura, mais non só, aparece pois comprometida na práctica deste proceso e moi vinculada ao Volkgeist a través do folklore. Desta práctica artística, que non deixou de acompañar o proceso dende o provincialismo, e tamén desta vinculación ideolóxica derivan unhas «regras da arte». Estas son producidas polos axentes que se van contituíndo en campo social e formando un auténtico campo de produción ideolóxico, político e cultural que, como todo campo, a medida que se vai desenvolvendo, vai creando tensións internas previsíbeis entre intelectuais, políticos e artistas que constitúen a cerna de campos que (...) tenden á súa autonomía. Estas «regras da arte» estaban asumidas sobre todo na práctica implícita, mais tamén son con frecuencia formuladas polos ideólogos do nacionalismo (Figueroa 2010: 58).

O imaxinario galego creado pola Xeración Nós opón a natureza e a terra representadas a través da paisaxe ${ }^{3}$ e indisolublemente vinculadas ao espírito do pobo (Volkgeist) e á tradición-, co mundo urbano e a modernidade, considerados alleos e inimigos das esencias da identidade galega. O Idilio coa terra sitúase, así, no cerne da súa estética. Isto faise claramente explícito na obra de Ramón Otero Pedrayo, por unha banda, e no pensamento de Vicente Risco, por outra, como se ten sinalado en diversas ocasións.

${ }^{2}$ Para un achegamento óptimo ao papel da paisaxe na configuración do imaxinario literario e nacional galego, é aconsellable a consulta do excelente ensaio de María López Sández (2008): Paisaxe e nación. A creación discursiva do territorio. Vigo: Galaxia.

${ }^{3}$ A paisaxe pode definirse como «a perspectivización estética do espazo como resultado da actividade artística e cultural» (López Sández 2008: 71). Deste xeito, «a dimensión estética, desde a dobre posibilidade do belo e o sublime, é un elemento consubstancial á propia paisaxe e amósase como unha característica compensatoria (e por tanto posibilitadora) da dominación industrial e a postergación do espazo implicada polo temporocentrismo» (López Sández 2008: 71). 
Así, na obra narrativa de Otero Pedrayo destaca o «significado simbólico da paisaxe» (Gómez 1993: 23), ata o punto de que a presenza dunha paisaxe pode chegar a condicionar o home (Gómez 1993: 21). Así, «a paisaxe é un elemento anovador do individuo porque o pon en contacto co máis eterno do Universo e porque o une coa vertente espiritual do país» (Gómez 1993: 22).

Por outra banda, no eido do pensamento foi Risco o responsable de expoñer e divulgar as «regras da arte» galega proxectadas desde a Xeración Nós, en artigos como «O sentimento da terra na raza galega» (Nós, 1, 4-9). Nese texto, teoriza «implicitamente sobre cales deben ser os temas e as regras da arte galega: a temática próxima ao mundo da natureza, sentimentos, paisaxe, folclore, costumes etcétera que teñen unha razón de ser e un contido específico» (Figueroa 2010: 65).

Para Risco, «esta vinculación mística coa terra (...) leva consigo un desgusto co mundo moderno do progreso e da cidade (a palabra chave é cosmopolitismo) e por conseguinte das súas manifestacións artísticas» (Figueroa 2010: 63). Risco vinculaba tamén o mundo urbano co socialismo, que refugaba dun xeito rotundo ${ }^{4}$. Décadas máis tarde, en plena etapa do galeguismo culturalista, Piñeiro e os homes da xeración Galaxia tamén se situaron no ronsel do anticomunismo, neste caso ligado ao europeísmo democrático.

$\mathrm{Na}$ Galicia de posguerra, Ramón Piñeiro era o líder intelectual ${ }^{5}$ do galeguismo - construído sobre as bases de Nós— así como tamén o verdadeiro axente central do precario sistema literario galego, á fronte da editorial Galaxia. Coa vista posta na recuperación do galeguismo e no restablecemento da continuidade rota coa guerra civil, Piñeiro coordinou a configuración dun ideario político-cultural (culturalismo) que propugnaba a posta en valor dos eixos fundamentais do ser galego, isto é, da «personalidade espiritual» de Galicia (Forcadela 2005). Para Piñeiro, a singularidade do pobo galego exprésase «nas raíces espirituais en que se afincan as creacións culturais que personalizan»e, polo tanto, identifican ese pobo concreto e fronte a calquera outro (González 2003: 16).

${ }^{4}$ «Non colle dúvida tampouco, de qu'o tono general da vida baixou, de que os homes y-as suas obras, adocénanse, de qu'as mais modernas conceiciós artístecas, polítecas, filosóficas e sociás, son d'un artificialismo sen grandeza, son plebeyas, son filisteas... O filisteu trunfa co capitalismo e co-a sua secuencia: o socialismo; trunfa na políteca e na cencia, na economía e na ética, na arte e no traballo.

A grande urbe é a incubadora do filisteu materialista, descreído, práutico, egoísta, cerebral, seco e duro, sen fantesía, cuando non vicioso, hedonista, eu chámolle: home degenerado na domesticidade urbana. [...] A grande urbe, malsana pr'o corpo, malsana pr'o esprito, mala meiga chuchona, zuga o sangre das naciós, vive parasitariamente, esgotando a vida das provincias, sorbendo as súas energías, o seu traballo, levando ós millores dos seus homes pr'esterilizalos logo, intoxicándoas co virus porco e fatal do cosmopolitismo qu'o corrompe todo, e que vai espallando a sua podre fedenta por todas partes. A grande urbe é a pústula maligna, o cancro que corroe ás nosas sociedás» (Risco, Vicente (1924): «A decadenza d'Oucidente II», El Pueblo Gallego 14, 1, apud Figueroa 2010: 63-64) .

5 A ideoloxía estética de Ramón Piñeiro desenvólvese en textos como «Carta a Álvaro Cunqueiro, trovador galego, falándolle dos males presentes de Europa e do seu remedio, desde a ladeira dun castro lugués», «Carta a Novoneyra» e «Carta a Daniel Cortezón Álvarez», entre outros. 
Para Piñeiro os «factores esenciais» de Galicia e, polo tanto, das súas manifestacións culturais, eran o lirismo, o humorismo, a saudade e o sentimento da paisaxe —entendida esta como natural e rural- . O pensamento culturalista promovido por Galaxia proxectaba sobre a paisaxe galega uns valores identitarios que, xunguíndose ao realismo na súa representación, a convertían nun elemento óptimo para a reivindicación culturalista: é a Terra. Proba da centralidade da paisaxe no proxecto estético do culturalismo galaxiano son os traballos recollidos no volume Paisaxe e cultura (Piñeiro 1965). Mais xa moito antes comezara a manifestarse nesa liña (por exemplo, en «O libro que nos debe Ánxel Fole», La Noche, 1949). Por outra banda, esa potenciación da paisaxe está relacionada co tratamento culto de motivos literarios folclóricos e populares (Bermúdez 2010), en consonancia coa consideración de que a paisaxe rural debía ser o escenario privilexiado das historias do pobo galego, depositario das esencias identitarias e da lingua propia. A «identificación sentimental coa Terra» (Piñeiro 1956) sitúase así no centro da estética piñeirista, na procura da «identificación plena e total co verdadeiro ser de Galicia» (Piñeiro 2005: 40-41, 19-11-1953).

Na vida da cultura galega, a Terra é un elemento aitivo i esencial. A nosa realidade cultural ven a ser a integración do humán e mailo telúrico, cualidade peculiarísima da nosa cultura, quizáis a máis difícil de comprender pra os alleos. Sin a base telúrica, a nosa espresión puramente humán é parcial, incompleta, sometida a perene vaguedade (Piñeiro 1956b: 16-17).

Na mesma liña, Xoán Rof Carballo, outro destacado intelectual de Galaxia, desenvolveu por extenso a vinculación entre identidade galega, saudade e paisaxe $^{6}$ en Mito e realidade da terra nai (1957).

\section{CARA A UN NOVO IMAXINARIO. FUNDAMENTOS ESTÉTICOS DE XOHÁN CASAL}

Pola súa banda, Xohán Casal propón un novo rumbo, un novo imaxinario alternativo, ou mellor, complementario e superador do «Idilio coa paisaxe» e a Natureza galega (Forcadela 2009b). En relación co cadro de oposicións vixente

\footnotetext{
${ }^{6}$ «A morriña, a saudade, a dor rumana, a morriña galega son sentimentos de pobos montañosos, ricos en bocarribeiras, en outeiros e en altos píncaros dende os que sempre se pode abesullar en toda a súa pureza un horizonte no que sobrancean, ennobrecidos, os elementos da paisaxe, entre eles as serras e cadeas montañosas azuleando na lonxanía. Trátase tamén dun sentimento de pobos que habitan países verdes e húmidos, nos que a natureza se amostra non no seu encoiro xeolóxico senón enfeitada coa roupaxe vexetal, non coma un reino de penedos e cristais, de irtas formas minerais, senón coma un mundo decote revestido polo verde milagre da vida. Pero, ademais, este mundo verde ha conservar, para ser saudoso, o carácter da natureza; o calco do home, a impronta do xardineiro ou do hortelán han ser escasas. Soamente así actúa en nós en forma sagrada, en forma dese «verde sagrado» que nos anova e nos avivece — do que falara ese poeta sorprendente que foi Hölderlin-, trasmitíndonos arreo un oculto celme que pon en comunicación o noso sangue coa vida vexetal que nos rodea» (Rof 1957: 42, apud López Sández 2008: 79-80).
} 
nos imaxinarios literarios na súa época — tradición-autóctono, tradición-alleo, modernidade-autóctono e modernidade-alleo (Forcadela 2009)_, Casal tende á conciliación, isto é, á superación da polarización: admite que desde o autóctono se pode asumir tanto a tradición como a modernidade. O propio, o autóctono pode provir tanto da tradición como da modernidade, pois a autenticidade vén dada pola percepción.

A nosa sensibilidade non deixa xipar7o me[11]or pulo da Natureza esté onde esté. No mar, no campo ou na cibdade. O galego e un «apreixador» da natureza - como o é da morte e da divinidade (Casal, «A carón da Natureza. Notas encol da paisaxe na novela galega», s/d, Real Academia Galega).

Refuga, en todo caso, de xeito insistente aquilo que é alleo a Galicia, aquilo que non se produce na realidade de Galicia, como expón en diversos textos. Representa a procura dunha autenticidade viva, dinámica, en movemento, como a sociedade galega na súa época, en plena convulsión transformadora polo tránsito do rural ao urbano. Así, Casal afirma significativamente nunha carta a Xosé Luís Franco Grande que as súas referencias de «galeguidade» ou «galicidade», como escribira Franco Grande- diverxen das que se poidan ter en Xelmírez: «eu ch'ando pol-os peiraos cos homes chegados do mar, ou cos obreiros, positivistas, materiales (...), pro eu sei ouvir a verdadeira poesía que acochan as suas verbas» (Bermúdez 2005; Bermúdez 2010: 72). Pola súa clase social e polas determinacións da doenza que o había levar á morte, non é probable que Casal convivise moito cos pescadores e obreiros, mais resulta claro que as clases traballadoras urbanas forman parte do seu universo vital, por integraren o seu mesmo hábitat urbano e porque Casal non refuga telas en conta na súa poética.

Con todo, os contos escolmados por Reimundo Patiño e Isaac Díaz Pardo n'O camiño de abaixo (1970) non se caracterizan por unha presenza maioritaria da paisaxe urbana habitada. En todo caso, non faltan as pezas en que a cidade é protagonista relevante: así acontece en relatos como «O Crego» ou, de xeito matizado, en «Maran Atha» (Bermúdez 2005). Emporiso, non é descartable que entre os manuscritos e mecanoscritos inéditos de Casal poidan aparecer obras cun máis marcado carácter urbano.

Casal traballou nun bosquexo de estética que continúa situando nunha posición central o elemento popular, mais tomando como base un concepto de pobo non estritamente coincidente co galaxiano, como veremos a través dos seus textos. Así, para el o pobo galego - ao que pretende facer protagonista do seu proxecto literario- está formado polo conxunto das clases populares e traba-

7 «Xipar» é voz propia do galego asturiano. Segundo Bernardo Acevedo y Huelves e Marcelino Fernández y Fernández (1932): Vocabulario del bable de occidente, «xipar: Escaparse un ser que debía estar preso: Xipóu el páxaro da xaula. Xipóu el preso da cárcel». Fonte: Dicionario de dicionarios, http://sli.uvigo.es/ddd [Última consulta: 12-7-2011]. Probablemente Casal non coñeceu o termo de viva voz, senón grazas a ese Vocabulario. 
lladoras, mais non exclusivamente as rurais (os labregos nas aldeas), senón tamén as que xa se desenvolven nun hábitat urbano ${ }^{8}$. Por iso, afirma

Eu non coido que natureza háchase n'unha descrizón «panoramica» d'unha paisaxe, senon nos pulos silandeiros que abrollan a cotio na nosa vida — no campo ou na vila—. Natureza e home son eiquí a mesma cousa. Por iso o galego humanizou o campo, por iso a cibdade é tan preto da natureza (Casal, «A carón da Natureza. Notas encol da paisaxe na novela galega», s/d., Real Academia Galega).

Reivindica a necesidade imperiosa da incorporación dunha parte do espazo galego que se vía excluída dos escenarios defendidos pola estética propugnada pola intelectualidade galaxiana: o espazo urbano, o hábitat do que están formando parte cada vez máis galegos, por causa das migracións do campo ás cidades que afecta á Galicia das décadas dos cincuenta e sesenta. Así, referíndose ao home galego, escribe:

Para il Amor-Natureza-Morte e Deus van xuntos - e agora ca vila xa non é un curruncho onde somentes latrican uns cantos homens inteleituales, se non, e pol-a contra - unha gaiola onde viven moitos homes asulagados n'un sono da Natureza, arrolados por ila, no seu traballo, mais sen atopala no seu hourizonte afumado e mouro. Sintíndoa vivindo con ila, mais sen podel-a ollar.

E o que cumpre e facela novela distes homes e pol-o tanto d'iste ambente. E non deixar xipar a Natureza, que é a que fai qu'inda xexan galegos, senón apreixala nos seus miudos e complexos retrincos (Casal, «A carón da Natureza. Notas encol da paisaxe na novela galega», s/d, Real Academia Galega).

Xa que logo, a postura de Xohán Casal, malia a súa xuventude e o feito de atoparse nunha cidade como A Coruña, non é de discípulo disciplinado da intelectualidade galaxiana, nin seguidor das directrices ideolóxicas desenvoltas en Compostela. Pola contra, busca a configuración dun pensamento propio servíndose do intercambio de ideas (fundamentalmente epistolar) con amigos como Reimundo Patiño, Xosé Luís Franco Grande e Manuel María (Bermúdez 2005).

A tua poesía gostóume moito, e sobor iso teríamos moito que falar, compría falar abondo de M[anuel] M[aría] e da Saudade. Discutir ó Piñeiro e estabrecer de novo a nosa posición. Dende logo é de combate (Carta a Reimundo Patiño9, 27-9-1958, Real Academia Galega).

${ }^{8}$ Isto contraponse á concepción do espazo en relación coa identidade galega materializada nos textos dun autor paradigmático da Xeración Nós, Ramón Otero Pedrayo, quen ademais representou a continuidade coa etapa da preguerra. A crítica ten posto de manifesto que, nalgúns dos seus relatos, a «aldea é o espacio do cal hai que partir para chegar a unha identificación total con Galicia» (Gómez 1993: 24).

9 Esta carta está datada con posterioridade á interesantísima correspondencia de Casal con Xosé Luís Franco Grande, na que se produce un intercambio intelectual darredor de aspectos identitarios, filosóficos e estéticos, darredor do pensamento de Ramón Piñeiro e da escrita literaria, entre outros temas (Bermúdez 2005). 
Como vemos, para Casal os factores identificadores de Galicia non eran necesariamente os mesmos que na estética galaxiana. Casal propuña un modelo de literatura diferente, que constituía unha novidade no seu momento e que implicaba outro concepto de identidade galega, urbana e popular. Neste sentido, representa unha posición estético-ideolóxica que contrasta co modelo piñeirista no que se refire á configuración da identidade colectiva. Con todo, estas reflexións quedaron sen consecuencias dado que estaban aínda en proceso de maduración, por unha banda, e que careceron de difusión - ao circunscribirse ao ámbito do privado (xornais, correspondencia persoal)—, por outra.

\section{PAISAXE E CIDADE. A REPRESENTACIÓN DA GALICIA URBANA}

Para Casal, resultaba fundamental definir e clarificar a relación entre cidade e Natureza, para integrar os hábitats urbanos como natureza urbana. Para este labor, toma a Charles Dickens como modelo e referencia:

Dickens foi un «apreixador» da Natureza na cibdade. A Natureza xurde na sua obra supetamente como relembro da infanza, coma conversa, sono ou paseio. Por unha cousa ou outra as vilas de $\mathrm{Ch}[$ arles] Dickens están enchidas da Natureza (Casal, «A carón da Natureza. Notas encol da paisaxe na novela galega», s/d, Real Academia Galega).

A vinculación entre galeguidade, Natureza e relixión era directa para Casal. Nacería dunha singular capacidade de percepción do galego. Nesta liña, desenvolve unha extensa reflexión, orixinal e innovadora na época:

O galego é un «apreixador» da natureza — como o é da morte e da divinidade-. Para il Amor-Natureza-Morte e Deus van xuntos —e agora ca vila xa non é un curruncho onde somentes latrican uns cantos homens inteleituales, se non, e pol-a contra - unha gaiola onde viven moitos homes asulagados n'un sono da Natureza, arrolados por ila, no seu traballo, mais sen atopala no seu hourizonte afumado e mouro. Sintíndoa vivindo con ila, mais sen podel-a ollar.

E o que cumpre e facela novela distes homes e pol-o tanto d'iste ambente ${ }^{10}$. E non deixar xipar a Natureza, que é a que fai qu'inda xexan galegos, senón apreixala nos seus miudos e complexos retrincos.

Eu non coido que natureza háchase n'unha descrizón «panoramica» d'unha paisaxe, senon nos pulos silandeiros que abrollan a cotio na nosa vida - no campo ou na vila-. Natureza e home son eiquí a mesma cousa. Por iso o galego humanizou o campo, por iso a cibdade é tan preto da natureza (Casal, «A carón da Natureza. Notas encol da paisaxe na novela galega», s/d, Real Academia Galega).

${ }^{10}$ Destaque noso. 
Casal tenta definir a cidade galega, un espazo mixto e en progreso, que aínda se atopa moi próximo do rural, no que afinca as súas raíces e co que interactúa. Sería unha especie de híbrido entre o rural tradicional e o universo obreiro e urbano. Deste xeito, encárase unha superación da oposición rural-urbano, ao tempo que se denuncia a existencia dun esteticismo simple que identifica beleza con arte (o belo co artístico). Sitúase así Casal na liña da estética contemporánea, que se estaba a materializar no ámbito occidental tanto nas artes plásticas como noutras manifestacións ${ }^{11}$. En definitiva, Casal vai debullando unha reflexión darredor das claves dunha novela urbana galega:

Hai un prexuízo moi grande a iste respeito. «A cibdade e feia». Mais ¿óllase nunha obra de Arte que sexa feia ou bonita? É ista consideración un dos prexuízos máis ruíns do artista. ¿Logo o home vai a deixar a Natureza porque ista non sexa bonita? Namentras non sexa nemiga, namentras sexa «nosa» tera o mesmo valor unha paisaxe do campo ca unha da cidade.

¿Non hai froles? Olla-los nenos.

¿Non hai albres? Olla-los mastros da luz...

(...) A paisaxe das cibdades galegas quere o seu posto na novela de oxe. Ben está a poesía campestre. Mais a cibdade tamén ten a súa (Casal, «A carón da Natureza. Notas encol da paisaxe na novela galega», s/d, Real Academia Galega).

O cuestionamento estético de base que subxace no pensamento de Casal é, xa que logo, a superación dunha estética apolínea que identificaba un determinado canon de beleza con Arte, excluíndo o resto das producións «non belas». Está Casal en sintonía coas correntes estéticas contemporáneas, na pintura pola que Casal se interesou especialmente e coa que estaba en contacto grazas ao estudio de García Patiño- e noutras artes (de Francis Bacon a Jackson Pollock, pasando pola «beat generation», etc.).

\section{GALEGUISMO, ACCIÓN E ESQUERDA}

Fronte ao europeísmo e ao anticomunismo declarado do grupo piñeirista (Bermúdez 2001), no pensamento de Xohán Casal non se expresa rexeitamento ningún cara á esquerda. Pola contra, Casal explicita de xeito claro que galeguismo e esquerda ían da man. Neste sentido, era consciente do momento crítico que estaba a vivir o galeguismo de posguerra. Afirmaba así:

Nós somos galeguistas [e] cada día doume máis conta delo. Galeguistas mozos, novos, de unha xeneración que superou incruso o comunismo ruso. Decateime

${ }^{11}$ Ao longo de todos os escritos de Casal transparéntase un constante interese polas artes plásticas. Posuía un coñecemento moi apreciable sobre escultura e pintura. Compartía inquedanzas e reflexións com amigos como Reimundo Patiño, fundamentalmente, e visitaba con relativa frecuencia o estudio de García Patiño na Coruña, lugar de encontro de pintores e artistas (Bermúdez 2005). 
aquela noite na ría — namentres ouvía as amargas verbas do vello galeguistaque para nós todo aquello fica como un mapa histórico que asiñala o Fado indiscutibre e invariabre. Semella como si a historia de Galiza houbera percorrido xa unha das etapas máis longas da sua vida e que nos xa temos unha visión de conxunto que supera á dos devanceiros. As posibilidás que pechamos son infindas, pro incalculabres (Casal, «Notas para unha carta», s/d, Real Academia Galega).

Decántase por unha literatura comprometida, de acción. Así, manifesta en repetidas ocasións a súa admiración por Lois Seoane: «este é un dos escritores que máis admiro» (Carta a Neira Vilas, 14-2-1959, Real Academia Galega) ou «sinto que os seus livros foron definitivos para min, n'il topei a prasmación da miña ideia políteca», por exemplo). Dun xeito sen dúbida ben ousado na época, confésase de esquerdas e socialista:

Un día falando co M[anuel] M[aría] dicía il que o Seoane era «comunista» coma se fora un defeito- i eu díxenlle que o «comunismo» tería que sofrir a versión galega.

Eu inda qu'un señorito levo sangue «socialista» ou millor galeguista e cada vegada sinto o pulo políteco e relixioso máis punxente (Casal, Carta a Reimundo Patiño, 27-9-1958, Real Academia Galega).

Por tanto, na sensibilidade política de Casal, o comunismo pódese (e débese) interpretar tamén como propio, pódese «nacionalizar» e galeguizar, para facer del algo propio, autóctono. Pouco despois, xa falecido Casal e nos inicios da década dos sesenta, comezarían a agromar na clandestinidade os partidos nacionalistas de inspiración marxista (UPG, PSG). Mostrándose simpatizante das ideoloxías de esquerda e da súa incorporación á política, Casal sitúase en sintonía co grupo Brais Pinto e coa atmosfera política que conformaba o embrión das devanditas formacións marxistas. Por outra banda, fai unha valoración explicitamente negativa de Vicente Risco pola súa ideoloxía dereitista e expresa reticencias fronte a Álvaro Cunqueiro, polo mesmo motivo.

A Igresia e Franco tratan de minar o galeguismo. O galeguismo é unha creación eminentemente «izquierdista»-disto estou convencido-. É un movimiento que afirma unha vountade social. Como tal é obra escrusivamente de izquierdas. Xa houbera certo movimento estrano de «dereitas» —ilémbraste do que di Castelao coido que en Sempre en Galiza? - que capitaneaba o Sr. Risco. A filiación político-relixiosa do Risco era sospeitosa. Home de dereitas sería capaz de calquer traición de falta de integridade. Esto vai implícito nas «dereitas». A «metafísica» do «catolicismo» hispano é unha apodrecida morea de ideas e arelas escuras e fatales. Risco demostrou na Guerra -intre no que se definiron dereitas e esquerdas- que a sua filiación lle impedía pasar a raia da prudencia... - -iste é un xeito garimoso de falar- (Casal, «Notas para unha carta», s/d, Real Academia Galega).

En relación con Cunqueiro, establece relación entre ética e estética para manifestar o seu distanciamento do mindoniense en ambos os planos: 
A narración debe de ser direita e sen figuras poéticas. A poesía debe de xurdir coma un arrecendor. Toda isa enxurrada de verbas: «estrelecer, solpor, donas do corpo delgado, etc.», as deixo para Cunqueiro que ten moito que acochar. Pro eu só quero a sinceridade máisima (Carta a Franco Grande, 26-9-1957, Real Academia Galega).

Na base das fortes reservas e, mesmo, recriminacións de Casal a Cunqueiro sitúase a tendencia ideolóxica. Casal non parece perdoar o dereitismo do mindoniense, que opón ás figuras de Castelao e Alexandre Bóveda. Continúa afirmando:

Para min a manifestación máis vidal dun povo é a sua vountade histórica expresada en aición política i económica. Por eso teño tanta fe en Galiza. As Hirmandades da Fala foron ante todo covas de homes cheos de arelas políticas, máis que genéticas ou artísticas — cho demostra a ideia que regulou a formación da Academia Galega- E na política o que máis vale é a vida do home, a persoalidad, a integridá, a ética humán. Cáseque sempre a sua obra desaparece: está formada por esforzos, charlas, verbas, discursos, por angurias e pola sua propia morte. Postas nunha balanza toda a obra de Risco e de Cunqueiro non valen pola redención da Galiza o que o sangue de Bóveda zugado pola Terra (Casal, «Notas para unha carta», s/d, Real Academia Galega).

Para Casal, a literatura galega ten de ser unha literatura dinámica, orientada á acción, á actividade, a espertar e sacudir. Certamente, esta ideoloxía non nace da filosofía da saudade nin da tendencia culturalista. Neste sentido, afirmaba Casal:

Na literatura galega moitos ergueron a voz en prol d'unha enfesta, mais inda non abondan. Son poucos. A enfesta. O miragre é iste: ollar a realidade, e xa pol-a man que ollal-a realidade vai á Aición. Aición! Velahí o miragre i a enfesta. A úneca. (...) Poucos homes tivemos d'aición. Curros, Castelao e outros máis, pro inda son poucos. O que fixo un teñen que facelo todos. É ben certo que Castelao e outros moitos aituaron con toda a forza do seu corazón (...). Lois Seoane segue o camiño que Castelao abriu no seu máis grande esforzo (...).

Eu non sei onde irán a parar as ideias do señor Piñeiro e de todos os que hoxe andan a facer unha filosofía da Saudade... pro hai nas ideias do sr. Piñeiro certas suxerencias que non quero desaproveitar (Casal, «Diario», s/d, Real Academia Galega).

O compromiso sitúase no cerne da súa autopoética, como manifesta ao afirmar que no seu pensamento latexan «ideias novas de fondo alicerce social e mora», de xeito que a súa literatura «sempre será reita», «conscente e doorosamente viva» (Casal, Carta a Neira Vilas, 14-2-1959, Real Academia Galega). O seu proxecto literario concibe unha fusión entre compromiso social e espiritualidade relixiosa: «levarei pouco a pouco unha ideia miña â práitica: xunguirei ao Manoel María e ao Seoane -Pondal Curros-. E os obreiros retrincados do Fardel [de eisiliado] terán a visión profética e terribremente relixiosa do Advento» (Casal, «Notas encol da paisaxe galega», s/d, Real Academia Galega). 


\section{PECHE}

Aquí deixamos, polo de agora, esta primeira exploración do pensamento de Xohán Casal a través dos seus textos persoais. Abofé, estes novos textos poñen de manifesto con claridade o pensamento e a procura estética de Casal, narrador galego atrapado na penumbra abafante da «longa noite de pedra» franquista. A rotunda reivindicación dunha novela urbana galega ou a convicción esquerdista e profundamente nacionalista abrollan nas súas palabras dun xeito explícito e mesmo ousado, no marco represivo da época. Confírmanse así algunhas das claves éticas e estéticas que se detectan nos contos reunidos n'O camiño de abaixo, como o compromiso cos desfavorecidos e marxinais, a temática urbana e a vontade de condensación da mensaxe.

\section{BIBLIOGRAFÍA}

Alonso Girgado, L. (coord.) (1999): Actas das I Xornadas das Letras Galegas en Lisboa. Santiago de Compostela: CIRP-Xunta de Galicia-Universidade Nova de Lisboa-Sociedade Guilherme Cossoul.

Arquivo da Real Academia Galega. A Coruña.

Bermúdez Montes, M. ${ }^{a}$ T. (1999). «Xohán Casal na Nova Narrativa galega» in Alonso Girgado 1999.

- (ed.) (2001): Nasce un árbore / Memorias de Tains de Gonzalo Rodríguez Mourullo. Vigo: Xerais.

- (ed.) (2005): O camiño de abaixo de Xohán Casal. Vigo: Xerais.

- (2010): «Piñeiro e os albores da "nova narrativa" galega». Revista de lenguas y literaturas catalana, gallega y vasca (Anuario de filología catalana, gallega y vasca). XV. Madrid: UNED. 55-75.

Domínguez Mallo, L. (2010). «A historia literaria como discurso multifuncional: Achega ás funcións asumidas pola historia da literatura galega durante o franquismo». Galicia 21 Issue B'10.

Figueroa, A. (2010): Ideoloxía e autonomía no campo literario galego. Santiago de Compostela: Laiovento.

Forcadela, M. (1993): Manual e escolma da Nova Narrativa Galega. Santiago de Compostela: Sotelo Blanco.

- (2009): A mecánica da maxia. Ficción e ideoloxía en Álvaro Cunqueiro. Vigo: Galaxia.

- (2009b): «O crime perfecto de Ramón Otero Pedrayo». A Trabe de ouro n. ${ }^{\circ}$ 79. [http://uvigo.academia.edu/ManuelForcadela/Papers/180232/O_crime_perfecto_de_Ramon_Otero_Pedrayo] [Última consulta: 12-7-2011]

Franco Grande, X. L. (1985): Os anos escuros, I. A resistencia cultural da xeración da noite (1954-1960). Vigo: Xerais. 
Gómez Clemente, X. M. a (ed.) (1993): Narrativa breve. Ramón Otero Pedrayo. Vigo: Galaxia.

González Fernández, A. (2003): Ramón Piñeiro: dúas lecturas. Santiago de Compostela: Dirección Xeral de Política Linguíística, Centro Ramón Piñeiro para a Investigación en Humanidades.

González Millán, X. (1994): «Do nacionalismo literario a unha literatura nacional: hipóteses de traballo para un estudio institucional da literatura galega». Anuario de Estudos Literarios Galegos. 67-81.

López Sández, M. (2008): Paisaxe e nación. A creación discursiva do territorio. Vigo: Galaxia.

Noia Campos, M. ${ }^{a}$ C. (1992). A Nova Narrativa Galega. Vigo: Galaxia.

Patiño Mancebo, R. (1970). «Prólogo», in Xohán Casal, O camiño de abaixo. Sada-A Coruña: Ediciós do Castro.

Piñeiro, R. (1956a): «Carta a Daniel Cortezón Álvarez», in Cortezón, D., As covas do Rei Cintolo. Vigo: Galaxia.

- (1956b): «Carta a Novoneyra», in Novoneyra, U., Os Eidos. Vigo: Galaxia.

- (1965): Paisaxe e cultura, Vigo: Galaxia, Colección Ensaios.

- (1974): Olladas no futuro. Vigo: Galaxia.

- (2005): Cartas a un mozo galego. Correspondencia con Xosé Luís Allué 1953-1967, Vigo: Galaxia.

Real Academia Galega. Arquivo Xohán Casal.

Rof Carballo, X. (1957): Mito e realidade da terra nai. Vigo: Galaxia. 


\title{
ANEXOS: DOUS TEXTOS INÉDITOS DE XOHÁN CASAL ${ }^{12}$
}

\section{TEXTO 1: CARTA A REIMUNDO PATIÑO}

\author{
A Cruña, 27-9-58
}

Meu querido Patiño:

Escríboche dend'o estudo ${ }^{13}$, n'unha mañán do sol e nubens.

Hoxe según os meus proieitos debería d'estar no Ferrol onde Quique ${ }^{14}$, xa que iste non aparecéu por eiquí dend'o 7. Rescibín o día 20 unha carta sua onde dicíame que non podería vir — nen tampouco o día 4 de Octobro- e que foras ti aló. Pensei en ir eu, máis tiven moitas ansias cos eisámenes - iunha semá! — e rematei pouco menos qu'esfolado — rematei onte-. Hoxe tiña que sair âs 8 da mañá e coma levei a noite sen pegar ollo non acordei deica as 9 . Amáis, inopinadamente, papei onte unha bebedeira que por pouco dou o pasamento. Deume relixiosa e botei un sermón sobor teoloxía galega que arrepiei a toda a miña familia.

Parece ser que desenrolei unha teoría místeca de moito rumbo... total que non puiden ir a Ferrol. E non sei como faremos. Ao mellor inda é tempo para o sábado que ven e vou. Non sei.

N'iste tempo sen acougo posibre, onde non fago máis que loitar - loitamos, non si? - vou contra relox. Non escribo, nen pinto, nen traballo. Mais non por falla de pulos, se non máis ben por eisceso d'ideias e cousas novas. Iste ano entrei n'un tempo de formación humán. Pouco a pouco van callando no meu ser todal-as cousas que o forman. Nótome brandiño. Certamente, coido, inda non é tempo de [tomalo] coma demasiado importante, nen de moita fondura. Hoxe mesmo estóu nunha loita maina, estou n'iste estudo outo e soitario onde cheguei fará cáseque un ano non sei se por sorte ou disgracia, e onde acobíllase a muller da miña vida. Co-ela vou tendo, Patiño, unha loita a relox, sen nome. E ollo craramente o meu derradeiro fracaso.

As vegadas penso que o «fracaso» verdadeiro non debe de nascer d'un coutamento inicial, senon d'un vivir preno. Agardo por il facéndome forte —e sei, porque Deus mo dixo, que daráme tempo para elo- coma quen agarda levar na face unha descárrega de perdición. Xa sei todo o vindeiro, pro inda así vou cara

${ }^{12}$ Respectamos a lingua orixinal de Casal, desde o convencemento de que proporciona un testemuño histórico significativo, ao reflectir o esforzo dun mozo inmerso nun ambiente castelanfalante por instalarse na lingua que quere facer propia, en plena ditadura franquista. Introducimos unicamente mínimas modificacións gráficas, encamiñadas á regularización de certos elementos: eliminamos os acentos circunflexos nos casos en que eran empregados (sen que houbese un criterio definido por parte de Casal) ou modificamos algunhas maiúsculas e minúsculas.

${ }^{13}$ Fala do estudio de pintura na Coruña de Raimundo García Patiño, no que se reunía a mocidade coruñesa con inquietudes artísticas e ao que adoitaba acudir Casal.

${ }^{14}$ Enrique Iglesias Conde, un dos amigos máis próximos de Casal. 
a il ledo. E a miña vida vaise erguendo rexa. Sigo a madurecer o ¿Crego» $^{15}$. N'ista invernía todo irá xurdiamente. Teño un fero pran de traballo. Hei d'acadar unha obxetividade «narrativa» que me faga domear os meus estados d'ánimo. E así farei unha serie de contos e pezas de teatro n'un aito -0 «Teatro do $36 »^{16}-$ que coido me farán moito ben. N'istes traballos tocarei moitos temas — dende a (...) duns galeguistas que queren fuxir n'unha barca en San Pedro ${ }^{17}$, deica o neno que soterra unha rolada en vida, ou a familia obreira que pasa mil privaciós por mercar unha arradio. Así terei cuberto un ano, aproisimadamente, de traballo e produición.

Antramentras, levarei pouco a pouco unha ideia miña â práitica: xunguirei ao Manoel María e ao Seoane - Pondal Curros. E os obreiros retrincados do Fardel $[\text { de eisiliado }]^{18}$ terán a visión profética e terribremente relixiosa do $A d$ vento $^{19} \ldots$

Estóu seguro de que ao fallo xurdirá en min aquello que deica hoxe fallóu e que impediume rematar ningunha obra.

A nosa ideia do «barroco» ten en min agora unha «nova» versión. Non traballarei cas verbas, nen cas oraciós, senon mais ben cas ideias: Todal-as cousas son relativas. A vida pódese ollar dende moitos diversos puntos. Cecáis non sexa máis que a mesma cousa contada con verbas retorneadas —ou a mesma cousa contada con novas verbas áxiles e lizgairas...-. O meu leitor toparáse a cada intre c'unha negación ou dúbida de que inantes lera coma artículo de fé. Ao cabo desminto o que afirmei duas liñas inantes.

Ora as sardiñas asadas no prato do mariñeiro non son máis que xantar. Ora trócanse en peixes cheos da luz da lua c'un siñificado de lenda, e axiña son peixes de San Andrés... logo n'un bico ou n'un paseio de dous mozos á beira do mar. Ise paseio pódese trocar en soedade. Soedade do mozo — que ía ca rapaza, un tanto afastado, e levaba un paraugas na man - e soedade d'ela co seu traxe sen gracia, grande e tenro; soedade da muller sobor da terra...

Nebro $^{20}$ as tardiñas de resol en que leín ao B[ertold] Brecht na Granxa. Eu estaba sô, máis sentíache a ti cabo de mín, e malia ficar un tanto esmorecido embaixo dos eucaliptus, sentíame camiñar pol-a estrada d'Elviña ${ }^{21}$ e nebraba a tarde en que a percorrín cabo da miña moza, e as noites en que so, detíñame perto da Ponte da Pedra — onde hai unha grande poza — a ollar as herbas que me-

$15 \mathrm{O}$ breve relato «O crego» foi incluído na colección póstuma $O$ camiño de abaixo. Destaca por presentar un logrado e intenso retrato do desarraigo e da soidade nun ambiente urbano.

16 «Teatro do 36» era o proxecto teatral que Casal preparou longamente. Finalmente, este traballo de Casal nunca viu a luz.

${ }^{17}$ Seguramente se refire a San Pedro de Visma, parroquia do concello da Coruña que na época era eminentemente rural.

${ }^{18} \mathrm{O}$ volume Fardel de eisiliado de Luís Seoane foi publicado por edicións Ánxel Casal en Bos Aires, en 1952.

19 O poemario Advento de Manuel María publicouse en 1954. Marcou dun xeito moi profundo a Casal, como el afirma en diversos textos (Bermúdez 2005).

${ }^{20}$ Casal adoita empregar a forma «nebrar» como equivalente do verbo «lembrar».

${ }^{21}$ Parroquia do concello da Coruña, situada na periferia da cidade naquela época. 
draban da i-auga e as nubens que se refrexaban... En aquelas tardes traguía eu un doce sabor coma ao pan e viño xantados n'un bodegón do camiño... dígoche que isto todo está drentro d'un prato de sardiñas azúes e verdes e roxas, sobor unhas flamas de cores acesos e marelos. Ti as pintaches. E nebro que querías que o prato fora como unha lua. Iste devalar, iste pensar «divagando», ten de ter máis fondura e consistencia, pro cando o conquira xa terei verbas retorneadas $e b a$ rrocas $^{22}$.

Fai días chamoume o Alfonso ${ }^{23}$. Escribiu moito - dixo-. Fixo a pelerinaxe das ánimas ao Santo Andrés ${ }^{24}$. O que me contóu é isto:

Xa no cabo do poema as ánimas van chegando á eirexa. Os vivos durmen ao redor do tempro e as ánimas van chegando deica o santo que as agarda en pé na porta. Todas dinlle os seus nomes - imos ti i eu, o Quique e o Alfonso, etc.-, e así van facendo unha longa e interminabel «lista» de nomes... mulleres, nenos, homes, vellos, todos os que na vida foron corpo mortal van dicindo os seus nomes ao santo. Logo dous anxos ábrenlles as portas do Ceio i entran na Groria. Na súa andaina - na noite- os peixes dourados choutan fora das augas do mar... sal o sol e n'il — na noite— ollan a Deus.

Tamén fixo un livriño de poémas curtos eistraordinarios. Cecáis sirva para o «Brais-Pinto».

O dia 15 rescibín o Brais Pinto $^{25}$ — xa llo emprestei ó teu pai- i escuso de decirche que parecéume verdadeiramente eistraordinario. Os teus dibuxos son bs, moi principalmente a testa. Fiquei sulprendido. Agora coido có M[anuel] M[aría] que Brais Pinto — ben rexido — debe de dar a loita aos «mercachifles» que andan pol-o mundo a perdel-as almas (xa m'entendes). Eu coido que ti debes afincar ben os teus pés en Brais Pinto - pol-o menos ún-e logo prepararche para abrir ben as pernas.

Outra cousa boa é o libro do $(\ldots)^{26}$. Cousa para ollar con tempo e rillar a modo, porque haino que rillar e desbotar moitas cousas. Sinto medo de ser eu en certo modo seu herdeiro.

O do Seoane tamén gostóume. E sinto que os seus livros foron definitivos para min, n’il topei a prasmación da miña ideia políteca. Un día falando co

${ }^{22}$ Reflectimos por medio da cursiva os subliñados no manuscrito de Casal.

${ }^{23}$ Refírese a un dos seus mellores amigos, o poeta coruñés Alfonso Gallego (Bermúdez 2005).

${ }^{24}$ Santo Andrés de Teixido, lugar de romaría tradicional na costa norte de Galicia.

25 Alude á unha publicación feita polo grupo de mozos galegos de esquerdas en Madrid Brais Pinto (fundado en 1958 e formado por Xosé Luís Méndez Ferrín, Reimundo Patiño, Alexandre Cribeiro, Bernardino Graña, Xosé Fernández Ferreiro, Bautista Álvarez, Ramón Lorenzo, César Arias, Herminio Barreiro e «Ben-Cho-Shey»). En 1958 publicaron o poemario de Ramón Otero Pedrayo Bocarribeira (poemas para ler e queimar).

${ }^{26}$ O nome do escritor, aparentemente estranxeiro (inglés ou alemán) resúltanos ilexible. 
M[anuel] M[aría] dicía il que o Seoane era «comunista» — coma se fora un defeito- i eu díxenlle que o «comunismo» tería que sofrir a versión galega.

Eu inda qu'un señorito levo sangue «socialista» ou millor galeguista e cada vegada sinto o pulo políteco e relixioso máis punxente.

N'iste tempo que resta d'estar afastados acadaremos o madurecimento humán necesario para non rozar e cando voltemos a xunguirnos faremos xa o noso traballo a toda vela.

Eu non penso perder un minuto n'iste inverno que ven, e quero callar o meu caraiter no posibre.

Coido que ti e máis eu, inda que non vaiamos «atados», faremos de galos mañanceiros. Compre aproveitar o tempo.

Eu co gallo de «estudar» coloqueime nun intre terribre. Ti non sabes a loita que levo. Pro é unha loita segura de vencer, é unha certidume «racional» de acadar o cabo. A seguridade perfeita d'unha vitoria.

E xa con esto remato a carta. É de noite. Veu o Quique impensadamente. Falamos i escribiuche a carta que vai de seguido ${ }^{27}$.

Con ela xa remato a presente. A ver si na proisima — co vagar d'istes pirmeiros días do outono- mándoche algún escrito meu.

A tua poesía gostóume moito, e sobor iso teríamos moito que falar, compría falar abondo de M[anuel] M[aría] e da Saudade. Discutir ó Piñeiro e estabrecer de novo a nosa posición. Dende logo é de combate. Axiña escribirei.

Tereiche ao corrente de canto faga, antramentras leva unha aperta do teu amigo.

Xohan Casal

${ }^{27}$ Non se transcribe ese fragmento de Enrique Iglesias por posuír carácter persoal e non engadir contidos de relevancia para o estudo da figura literaria de Xohán Casal. 


\section{TEXTO 2: «A CARÓN DA NATUREZA. NOTAS ENCOL DA PAISAXE NA NOVELA GALEGA» (S/D)}

Enceto c'unhas verbas de Ch[arles] Dickens na sua Vida e aventuras de Nicolás Nickleby ${ }^{28}$. É mister Linkinwater quen fala, velahí o que di: «iO campo! ¿non sabe vostede qu'en ningures mais qu'en Londres podería eu disfroitar d'un páteo coma iste baixo a fiestra do meu carto?». E mister Linkinwater fala co señor Nickleby sobor as belezas do campo e da cibdade e inda cas ideias de Mr. Linkinwater son un pouco — na tona— febles, a sua ouservazón é moi certa. Para il —home da cibdade — en ni[n]gures pode disfroitar millor da Natureza qu'en a cibdade.

Ista é unha das faces mais interesantes da novela de $\mathrm{Ch}$ [arles] Dickens, con relaizón â nosa. Dickens foi un «apreixador» da Natureza na cibdade. A Natureza xurde na sua obra supetamente como relembro da infanza, coma conversa, sono ou paseio. Por unha cousa ou outra as vilas de Ch[arles] Dickens están enchidas da Natureza.

Emporiso teñen unha paisaxe orixinal na que abrollan cás, albres, ruas estreitas, campos e hourizontes largacíos, ruído das paradas e dos carruaxes, e a choiva que tomba no teito e percorre logo o alcatruz e os vidros.

Toda a vila está pendente da Natureza que lle dá vida.

Dickens é un moi bo paisaxista. Léndoo ollase que a vila non está tan alonxada da Natureza coma moitos din.

A Natureza rebule nas suas ruas, nas cas[as], nas i-almas. Miuda e pequena vaise espallando en retrincos polo relato ata adonarse d'il.

Van Gogh gustou da obra de Dickens, e non sô pol-o seu contido human, senon tamén pol-as suas paisaxes, os seus ceos grises, as suas choivas e as suas nubens terribels que fan celmal-as novelas humedén. E fan polo tanto de Dickens, como Van Gogh amaría, un moi boo coorista.

«Qu'o mellor prisma —o prisma e o pai da luz-coor — e un ambente acugulado d'humedén». Mais estou develando co tema.

A nosa sensibilidade non deixa $x \operatorname{car}^{29} \mathrm{o}$ meor pulo da Natureza está onde esté. No mar, no campo ou na cibdade. O galego e un «apreixador» da natureza - como o é da morte e da divinidade. Para il Amor-Natureza-Morte e Deus van xuntos -e agora ca vila xa non é un curruncho onde somentes latrican uns cantos homens inteleituales, se non, e pol-a contra - unha gaiola onde viven moitos homes asulagados n'un sono da Natureza, arrolados por ila, no seu traballo, mais

${ }^{28}$ Terceira novela de Charles Dickens (1812-1870), publicada inicialmente por entregas entre 1838 e 1839. Céntrase nas vicisitudes da vida de Nicholas Nickleby, mozo orfo que debe ocuparse da súa nai e irmá, e recorre para isto ao seu tío Ralph, que exerce como antagonista. Mister Linkinwater é un dos protagonistas da novela.

${ }^{29}$ Escapar, no galego asturiano. 
sen atopala no seu hourizonte afumado e mouro. Sintíndoa vivindo con ila, mais sen podel-a ollar.

E o que cumpre e facela novela distes homes e pol-o tanto d'iste ambente. E non deixar xipar a Natureza, que é a que fai qu'inda xexan galegos, senón apreixala nos seus miudos e complexos retrincos.

Eu non coido que natureza háchase n'unha descrizón «panoramica» d'unha paisaxe, senon nos pulos silandeiros que abrollan a cotio na nosa vida - no campo ou na vila- . Natureza e home son eiquí a mesma cousa. Por iso o galego humanizou o campo, por iso a cibdade é tan preto da natureza.

Hai un prexuicio moi grande a iste respeito. «A cibdade e feia». Mais ¿ollase n'unha obra de Arte que sexa feia ou bonita? [É] ista consideración un dos prexuizos mais ruins do artista. ¿Logo o home va a deixar a Natureza porque ista non sexa bonita?

Namentras non sexa nemiga, namentras sexa «nosa» tera o mesmo valor unha paisaxe do campo c'unha da cidade.

¿Non hai froles? Ollal-os nenos.

¿Non hai albres? Ollal-os mastros da luz... O verdadeiro home [alonxa] a ialma da Natureza e non a tona. Lémbrome d'unhas verbas de B[ertrand] Russell sobor iste aspeito ao falar do home da cibdade: unha vegada rematada a sua xeira non pode, como o pastor de Milton ${ }^{30} \ll$ contar suas magoas baixo o espiño do val» porque non soe haber val preto da sua cás, e [«]se o hai está cheo de latas vellas». Velaí o fallo. ¿Que mais dará?

Istes versos de Klopstock ${ }^{31}$ son a mostra. Di Klopstock:

«Unha aurora...

... cando, rosada, xurde tras do comaro celmando seus cabelos latas d'un rocío purísimo...»

E digo eu: a Aurora, saíu sobor dos estercoleiros da fábrica de salazón celmando seus cabelos gotas dun rocío purísimo.

O home galego leva a paisaxe no seu esprito. Canto vai dos seus ollos fiestras endexamais pechas- [á] súa boca é paisaxe. Inda máis: é alma da paisaxe.

Iste home que pode facer humán unha máquina, iste home que — pola contra de outros - pode pintar nun lenzo o Deus_-máquina. Quero decir, que pode pintar unha máquina cun esprito tal que sexa un Christo. Iste home pode ollar na

${ }^{30}$ John Milton (1608-1674) foi un ensaísta e poeta inglés, autor d'O paraíso perdido (1667) e O paraíso recobrado (1671).

${ }^{31}$ Friedrich Gottlieb Klopstock (1724-1803 foi un poeta alemán, autor de obras de marcado carácter relixioso e espiritual. Teólogo de formación, era admirador entusiasta do poeta británico John Milton e publicou diversas odas, pezas teatrais e da epopea relixiosa Messias, extenso poema en vinte cantos que o consagrou no eido da poesía. Moi probablemente, foi o carácter relixioso e espiritual da súa poesía o que atraía a Casal. 
cibdade a verdadeira Natureza. Non fan falla hourizontes largacíos para quen no seu derradeiro alento os leva no seu esprito.

Emporiso a paisaxe das cibdades galegas quere o seu posto na novela d'oxe. Ben está a poesía campestre. Mais a cibdade tamén ten a súa. 